\title{
Auraptene, a Major Compound of Supercritical Fluid Extract of Phalsak (Citrus Hassaku Hort ex Tanaka), Induces Apoptosis through the Suppression of mTOR Pathways in Human Gastric Cancer SNU-1 Cells
}

\author{
Jeong Yong Moon, ${ }^{1}$ Hyeonji Kim, ${ }^{1}$ and Somi Kim Cho ${ }^{1,2}$ \\ ${ }^{1}$ Subtropical Horticulture Research Institute, Jeju National University, Jeju 690-756, Republic of Korea \\ ${ }^{2}$ Faculty of Biotechnology, College of Applied Life Science, SARI, Jeju National University, Jeju 690-756, Republic of Korea
}

Correspondence should be addressed to Somi Kim Cho; somikim@jejunu.ac.kr

Received 19 April 2015; Revised 21 June 2015; Accepted 15 July 2015

Academic Editor: Brett Froeliger

Copyright (C) 2015 Jeong Yong Moon et al. This is an open access article distributed under the Creative Commons Attribution License, which permits unrestricted use, distribution, and reproduction in any medium, provided the original work is properly cited.

\begin{abstract}
The supercritical extraction method is a widely used process to obtain volatile and nonvolatile compounds by avoiding thermal degradation and solvent residue in the extracts. In search of phytochemicals with potential therapeutic application in gastric cancer, the supercritical fluid extract (SFE) of phalsak (Citrus hassaku Hort ex Tanaka) fruits was analyzed by gas chromatography-mass spectrometry (GC-MS). Compositional analysis in comparison with the antiproliferative activities of peel and flesh suggested auraptene as the most prominent anticancer compound against gastric cancer cells. SNU-1 cells were the most susceptible to auraptene-induced toxicity among the tested gastric cancer cell lines. Auraptene induced the death of SNU-1 cells through apoptosis, as evidenced by the increased cell population in the sub-G1 phase, the appearance of fragmented nuclei, the proteolytic cleavage of caspase- 3 and poly(ADP-ribose) polymerase (PARP) protein, and depolarization of the mitochondrial membrane. Interestingly, auraptene induces an increase in the phosphorylation of Akt, which is reminiscent of the effect of rapamycin, the mTOR inhibitor that triggers a negative feedback loop on Akt/mTOR pathway. Taken together, these findings provide valuable insights into the anticancer effects of the SFE of the phalsak peel by revealing that auraptene, the major compound of it, induced apoptosis in accompanied with the inhibition of mTOR in SNU-1 cells.
\end{abstract}

\section{Introduction}

Gastric cancer is a common malignant tumor, which is increasingly being reported. It remains at the second leading cause of cancer related death in the world for a long time [1]. Although infection with Helicobacter pylori is considered to be the primary cause, the cause of gastric cancer is multifactorial. There are several complicated reasons for the occurrence of gastric cancer such as food habit, lifestyle, and tobacco smoking [2]. Further, overweight and obesity are also correlated with increased risk of gastric cancer [3]. On the other hand, consumption of fruits or vegetables has been shown long since to decrease the risk of gastric cancer regardless of the anatomical location and the histological type [4].

The supercritical carbon dioxide is generally used as an extraction solvent since $\mathrm{CO}_{2}$ is inert and low toxic and requires short extraction time. Because of several such advantages, nowadays supercritical fluid extract (SFE) method is increasingly being used in the food, pharmaceutical, and environmental engineering sectors [5]. Citrus has long been accepted as a rich source of anticancer compounds and several flavonoids have been reported to exhibit anticancer effect against various types of human cancer cells [6], especially the richest source of auraptene (7-geranyloxycoumarin) [7]. Auraptene has been known to have various pharmacological properties, such as cancer chemopreventive [8], antioxidant $[9,10]$, anti-inflammatory [11], antimicrobial, antigenotoxic, neuroprotective, and immunomodulatory properties in various animal models [7]. It has been reported to show apoptosis in human acute leukemia Jurkat T cells through ER stress mediated caspase- 8 activation followed by stimulation of caspase cascade [12]. Furthermore, it has been reported as a 
chemopreventive agent against cancers of liver, skin, tongue, esophagus, and colon in rodent models while its effect in human cancer is not yet fully understood [13]. Moreover, little is known about the mechanism responsible for the apoptotic activity of auraptene against gastric cancer cells.

In the present study, the cytotoxicity of SFE of phalsak (Citrus hassaku Hort ex Tanaka) fruit in the human gastric cancer SNU-1 cells was assessed. We determined for the first time that auraptene, the major compound of phalsak peel $\mathrm{SFE}$, induces cytotoxicity of SNU-1 cells with $\mathrm{IC}_{50}$ value $\leq$ $25 \mu \mathrm{M}$. These results suggest that auraptene positively regulates apoptotic signaling by downregulating the mTOR pathway via feedback activation on Akt in SNU-1 cells.

\section{Materials and Methods}

2.1. Preparation of SFE. Dried peel (280.4 g) and flesh (371.1 g) were loaded separately into a $1 \mathrm{~L}$ thick-walled stainless steel thimble extraction cell and extracted at $50^{\circ} \mathrm{C}$ for $2 \mathrm{~h}$. The extraction was performed using $\mathrm{CO}_{2}$ at 300 bar pressure in a diaphragm compressor (Haskell Co., Bellingham, WA, USA). The extracts (peel: $2.24 \mathrm{~g}$, flesh: $1.75 \mathrm{~g}$ ) were deposited in a separator attached to a metering valve and held in a circulating bath at $0^{\circ} \mathrm{C}$. Finally, the extracts were collected into a clean vial and stored in aliquots at $-20^{\circ} \mathrm{C}$ until analysis. The thawed sample was not frozen back for reuse.

2.2. Cell Culture. Human gastric cancer (AGS, MKN45, SNU-1, and SNU-16) cell lines were purchased from the Korean Cell Line Bank (KCLB, Seoul, Korea). Human embryonic kidney (HEK-293T) cells were kindly provided by Professor Jae Hoon Kim at the Faculty of Biotechnology, Jeju National University, Republic of Korea. Cells were maintained at $37^{\circ} \mathrm{C}$ in a humidified atmosphere under $5 \% \mathrm{CO}_{2}$ in RPMI 1640 or DMEM containing 10\% heat-inactivated FBS, $100 \mathrm{U} / \mathrm{mL}$ penicillin, and $100 \mu \mathrm{g} / \mathrm{mL}$ streptomycin. Exponentially grown cells were treated with various concentrations of the solvent fractions, as indicated.

2.3. Cell Viability Assay. Cells were maintained in a humidified incubator at $37^{\circ} \mathrm{C}$ in a $5 \% \mathrm{CO}_{2}$ atmosphere. Antiproliferative activity was determined by the cell viability assay. The effect of the samples on the viability of various cancer cell lines was determined by an MTT-based assay. Exponentialphase cells were collected and transferred to a 96-well microtiter plate $\left(2 \times 10^{3}-5 \times 10^{4}\right.$ cells per $\left.\mathrm{mL}\right)$ to detect cytotoxicity in the gastric cancer cell lines. The cells were incubated for 2 days with various concentrations of the fruit extract. The supercritical fluid extract was dissolved in DMSO and diluted in PBS to obtain a stock solution, which was stored at $-20^{\circ} \mathrm{C}$. After the incubation, $0.1 \mathrm{mg}$ MTT (Sigma, St. Louis, MO, USA) was added to each well, and the cells were incubated at $37^{\circ} \mathrm{C}$ for $4 \mathrm{~h}$. The medium was carefully removed. DMSO $(150 \mu \mathrm{L})$ was added to each well to dissolve the formazan crystals. The plates were read at $570 \mathrm{~nm}$ after the crystal had dissolved completely, using a Sunrise microplate reader (Sunrise, Tecan, Salzburg, Austria). The percent cell viability was calculated based on the following formula: mean value of (control group - treated group/control group) $\times 100 \%$. All results were assessed in triplicate for each concentration.

2.4. Gas Chromatography-Mass Spectrometry (GC-MS) Analysis. GC-MS analysis was carried out using a Shimadzu GCMS (Model QP-2010, Shimadzu Co., Kyoto, Japan) in the electron impact mode. The capillary column was an Rtx-5MS (30 m length, $0.25 \mathrm{~mm}$ internal diameter, and $0.25 \mu \mathrm{M}$ film thicknesses). Ionization was set at $70 \mathrm{eV}$ and injector and detector were set at 250 and $290^{\circ} \mathrm{C}$, respectively. The oven temperature was set at $60^{\circ} \mathrm{C}$ (isothermal for $2 \mathrm{~min}$ ) and was ramped up to $250^{\circ} \mathrm{C}$ at $5^{\circ} \mathrm{C} / \mathrm{min}$ (isothermal for $2 \mathrm{~min}$ ) and up to $310^{\circ} \mathrm{C}$ at $8^{\circ} \mathrm{C} / \mathrm{min}$ (isothermal for $5 \mathrm{~min}$ ). Helium was used as the carrier gas at $1 \mathrm{~mL} / \mathrm{min}$ with an injector volume of $1 \mu \mathrm{L}$ (1:10 split ratio). Supercritical fractions were dissolved in hexane $(1 \mathrm{mg} / \mathrm{mL})$, filtered through $0.2 \mu \mathrm{m}$ syringe filter (Advantec, Tokyo, Japan), and an aliquot of sample was injected into the GC-MS. The mass spectra of each compound were tentatively identified by comparing with Wiley 7 th edited library data of the GC-MS system. The compound identity was further confirmed with the retention indices (RI) of standard compounds. RI values on the column were determined using a mixture of alkanes $\left(\mathrm{C}_{7}-\mathrm{C}_{30}\right)$ which were run under identical conditions.

2.5. Microscopic Observation of Nuclear Morphology. Cells, placed in 6-well plates at $5 \times 10^{4}$ cells $/ \mathrm{mL}$, were treated with the samples. After $24 \mathrm{~h}, 10 \mu \mathrm{M}$ of Hoechst 33342, a DNAspecific fluorescent dye, was added to the solution in each well and the plates were incubated for $10 \mathrm{~min}$ at $37^{\circ} \mathrm{C}$. The stained cells were then observed under an Olympus fluorescence microscope.

2.6. Flow Cytometric Analysis. To determine cell cycle distribution analysis, $5 \times 10^{4}$ cells $/ \mathrm{mL}$ cells were plated in 6 -well plate and treated with the samples for $24 \mathrm{~h}$. After treatment, the cells were collected, fixed in 70\% ethanol, washed in PBS (2 mM EDTA), resuspended in $1 \mathrm{~mL}$ PBS containing $1 \mathrm{mg} / \mathrm{mL}$ RNase and $50 \mathrm{mg} / \mathrm{mL}$ propidium iodide, incubated in the dark for $30 \mathrm{~min}$ at $37^{\circ} \mathrm{C}$, and analyzed by FACS caliber flow cytometry (Becton Dickinson, USA). Data from 10,000 cells were collected for each data file.

2.7. JC-1 Analysis. Mitochondrial membrane potential $(\Delta \Psi \mathrm{m})$ was measured by flow cytometry using JC-1 staining. After treatment of the sample, the cells were incubated with $1 \mu \mathrm{L}$ of JC-1. After $10 \mathrm{~min}$, cells were washed twice with PBS and immediately subjected to flow cytometric analysis. The percentage of cells in the high-red region or low-red and high-green region was measured under the different treatments.

2.8. Western Blot Analysis. After treatment, the cells were collected and washed twice with cold PBS. The cells were then lysed in lysis buffer (50 mM Tris- $\mathrm{HCl}, \mathrm{pH} 7.5,150 \mathrm{mM} \mathrm{NaCl}$, $1 \%$ Nonidet P-40, $2 \mathrm{mM}$ EDTA, $1 \mathrm{mM}$ EGTA, $1 \mathrm{mM} \mathrm{NaVO}$, $10 \mathrm{mM} \mathrm{NaF}, 1 \mathrm{mM}$ DTT, $1 \mathrm{mM}$ PMSF, $25 \mu \mathrm{g} / \mathrm{mL}$ aprotinin, and $25 \mu \mathrm{g} / \mathrm{mL}$ leupeptin) and kept on ice for $30 \mathrm{~min}$. The lysates 


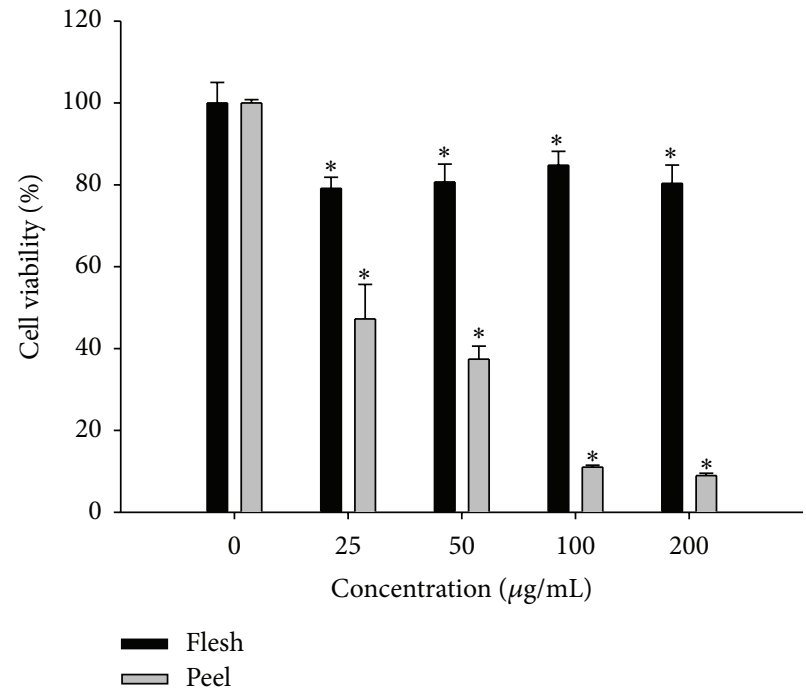

(a)

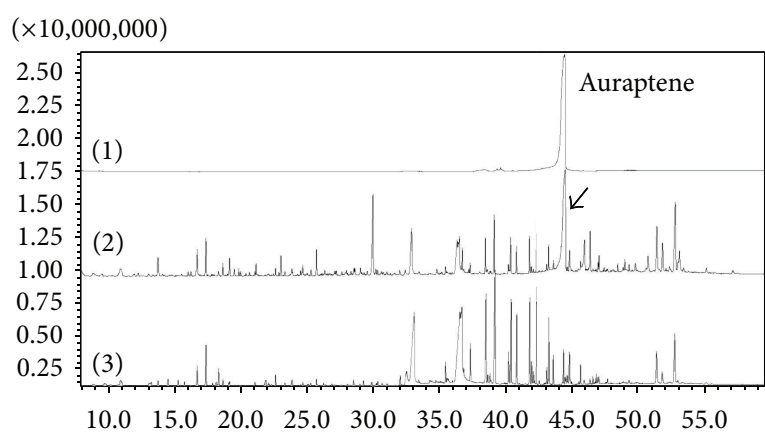

(b)

FIGURE 1: Cell viability on SNU-1 cells and GC-MS chromatogram of the SFEs of Jeju Citrus hassaku Hort ex Tanaka (phalsak). (a) Viability was determined on the basis of MTT reduction assay. (Data represent the means SD of at least four independent experiments. ${ }^{*} P<0.01$ indicate statistically significant differences versus control group.) (b) GC-MS chromatogram of SFEs. ((1) Auraptene standard peak, (2) SFE of phalsak peel, and (3) SFE of phalsak flesh; arrow indicates auraptene peak.)

were then centrifuged at $13,000 \times \mathrm{rpm}$ at $4^{\circ} \mathrm{C}$ for $30 \mathrm{~min}$; the supernatants were stored at $-70^{\circ} \mathrm{C}$ until use. The protein concentration was determined by the bicinchoninic acid (BCA) protein assay kit (Pierce, Rockford, IL, USA). Aliquots of the lysates (60-100 $\mu \mathrm{g}$ of protein) were separated by $7.5-15 \%$ SDS-PAGE and transferred onto a polyvinylidene difluoride (PVDF) membrane (Bio-RAD, HC, USA) using a glycine transfer buffer (192 mM glycine, $25 \mathrm{mM}$ Tris-HCl, pH 8.8, and $20 \%$ methanol $[\mathrm{v} / \mathrm{v}])$. After blocking with $5 \%$ nonfat dried milk, the membrane was incubated for $2 \mathrm{~h}$ with primary antibodies followed by $30 \mathrm{~min}$ with secondary antibodies in milk containing Tris-buffered saline (TBS) and $0.1 \%$ Tween 20 . All primary antibodies were used at a dilution of $1: 1,000$; HRPconjugated goat anti-rabbit IgG $(\mathrm{H}+\mathrm{L})$ and HRP-conjugated goat anti-mouse $\operatorname{IgG}$ were used as secondary antibodies at a dilution of 1:5,000. The PVDF membrane was then exposed to X-ray film (AGFA, Mortsel, Belgium), and the protein bands were detected using a WEST-ZOL plus Western Blot Detection System (iNtRON, Gyeonggi-do, Korea).

2.9. Statistical Analysis. All results were expressed as the mean \pm standard deviation. One-way analysis of variance using SPSS v 12.0 software package was applied. All assays were performed in triplicate. Values of ${ }^{*} P<0.01$ were considered to be statistically significant.

\section{Results}

3.1. Cytotoxic Effect and Chemical Composition of Supercritical Fluid Extracts. MTT assay was carried out to investigate the cytotoxic effect of SFEs of Citrus hassaku Hort ex Tanaka (phalsak) peel and flesh $(25-200 \mu \mathrm{g} / \mathrm{mL})$ against human gastric cancer SNU-1 cells. The cytotoxic effect of the peel fraction was significantly greater than the flesh fraction against the gastric cancer cells (Figure 1(a)). The GC-MS analysis of SFEs of phalsak revealed 49 compounds and 43 compounds in peel and flesh, respectively (Table 1). Auraptene was found to be the major compound in peel SFE, while almost no auraptene was detected in the flesh SFE (Figure 1(b)).

3.2. Cytotoxic Effect of Auraptene. Since the cytotoxic effect and the abundance of auraptene are significantly greater in the peel fraction than in the flesh fraction, we presume that auraptene is highly likely to be the most potent anticancer candidate present in the phalsak (Citrus hassaku Hort ex Tanaka) fruit. For this reason, we have studied the anticancer effects taking auraptene as a possible therapeutic candidate in the treatment of human gastric cancer. Although auraptene has previously been reported to have a potential of chemoprevention against various types of cancers such as liver, skin, tongue, esophagus, and colon in rodent models, its effect in human cancer is poorly reported [13]. This also substantiated our interest in anticancer effect of auraptene on human gastric cancer cells. As shown in Figure 2, auraptene reduced the viability of all types of tested gastric cancer cells in a dose-dependent manner. Among them, SNU-1 was the most sensitive with $\mathrm{IC}_{50}$ value $\leq 25 \mu \mathrm{M}$. In contrast, auraptene did not pose cytotoxic effect against noncancer cell lines HEK293T. Therefore, auraptene has high potential to treat gastric cancer cells without harming normal cells.

3.3. Effect of Auraptene on Cell Morphology, Cell Cycle Distribution, and $\Delta \Psi m$. Morphological changes such as cell shrinkage, blebbing, condensation, and fragmentation of 
TABLE 1: Identification of compounds present in supercritical fluid extract of phalsak fruit by GC-MS.

\begin{tabular}{|c|c|c|c|}
\hline Name $^{a}$ & $\mathrm{RT}^{\mathrm{b}}$ & Peel $^{\mathrm{c}}$ & Flesh $^{\mathrm{c}}$ \\
\hline$\beta$-myrcene & 8.031 & 0.34 & - \\
\hline 2-Octenal & 9.764 & - & 0.49 \\
\hline Linalool & 10.957 & 0.69 & 0.85 \\
\hline p-Menth-1-en-8-ol, (S)-(-)- & 13.776 & 1.39 & 0.41 \\
\hline 2,4-Dimethylbenzaldehyde & 14.529 & - & 0.42 \\
\hline 2-Ethylcyclohexanone & 15.299 & - & 0.34 \\
\hline (E)-2-Decenal & 15.777 & - & 0.21 \\
\hline$\alpha$-Citral & 16.057 & 0.22 & - \\
\hline (E,E)-2,4-Decadienal & 16.727 & 1.43 & 0.98 \\
\hline Octadecyl vinyl ether & 17.885 & - & 0.13 \\
\hline Citronellyl acetate & 18.321 & 0.28 & - \\
\hline 2,4-Dimethyl-5-oxo-heptanal & 18.350 & - & 0.87 \\
\hline Undec-2-enal & 18.654 & - & 0.28 \\
\hline Geranyl acetate & 19.164 & - & 0.22 \\
\hline$\beta$-cubebene & 19.517 & 0.39 & - \\
\hline Decylacetate & 19.853 & 0.27 & - \\
\hline Limonen-10-yl acetate & 19.999 & 0.18 & - \\
\hline trans-Caryophyllene & 20.373 & 0.10 & - \\
\hline Perilla acetate & 20.646 & 0.13 & - \\
\hline (E)-Geranylacetone & 21.049 & 0.16 & 0.16 \\
\hline 3,7-Dimethyloct-1-en-3,7-diol & 21.146 & 0.52 & - \\
\hline Oleic acid & 21.889 & - & 0.47 \\
\hline 2,4-Di-tert-butylphenol & 22.610 & 0.28 & 0.4 \\
\hline Sesquisabinene hydrate & 22.857 & 0.16 & - \\
\hline$\delta$-Cadinene & 23.026 & 0.81 & - \\
\hline Dihydroactinidiolide & 23.315 & 0.2 & 0.12 \\
\hline Lauric acid & 23.822 & 0.38 & 0.33 \\
\hline Nerolidol & 23.885 & 0.12 & - \\
\hline (-)-Caryophyllene oxide & 24.645 & 0.40 & 0.17 \\
\hline Diisobutylamine & 25.236 & - & 0.18 \\
\hline Spathulenol & 25.681 & - & 0.21 \\
\hline$\beta$-sinensal & 27.172 & 0.13 & - \\
\hline Duvatriendiol & 27.916 & 0.20 & - \\
\hline Myristic acid & 28.487 & 0.28 & - \\
\hline 6-Tridecen-6-al & 28.556 & 0.25 & - \\
\hline (-)-Loliolide & 28.989 & 0.26 & - \\
\hline N-Butylbenzenesulfonamide & 29.256 & 0.13 & 0.24 \\
\hline Nootkatone & 29.93 & 5.83 & 0.15 \\
\hline Platambin & 30.964 & 0.12 & - \\
\hline Leden alkohol & 31.551 & 0.25 & - \\
\hline Farnesyl acetone A & 31.922 & 0.31 & - \\
\hline Methyl palmitate & 31.974 & - & 0.53 \\
\hline Heptadecene-(8)-carbonic acid-(1) & 32.349 & 0.37 & - \\
\hline 2-hydroxycyclopentadecan-1-one & 32.433 & - & 1.79 \\
\hline Palmitic acid & 32.830 & 4.56 & - \\
\hline Pentadecylic acid & 33.024 & - & 10.77 \\
\hline Ethyl palmitate & 33.360 & - & 0.11 \\
\hline Pentadecanoic acid, 14-bromo- & 34.216 & - & 0.2 \\
\hline cis-Octadec-9-enal & 34.360 & - & 0.29 \\
\hline 6-Tridecen-6-al & 34.730 & 0.36 & - \\
\hline
\end{tabular}


TABle 1: Continued.

\begin{tabular}{|c|c|c|c|}
\hline Name $^{\mathrm{a}}$ & $\mathrm{RT}^{\mathrm{b}}$ & $\mathrm{Peel}^{\mathrm{c}}$ & Flesh $^{\mathrm{c}}$ \\
\hline Manool & 34.985 & - & 0.37 \\
\hline n-Nonadecane & 35.381 & - & 1.48 \\
\hline Methyl oleate & 35.575 & 0.23 & - \\
\hline Methyl linoleate & 36.248 & 3.61 & - \\
\hline Heptadecene-(8)-carbonic acid-(1) & 36.403 & 3.46 & - \\
\hline Oleic acid & 36.599 & - & 20.79 \\
\hline Methyldiethylborane & 36.631 & 1.23 & - \\
\hline N-Hentetracontanol-1 & 37.985 & - & 0.45 \\
\hline n-Hexatriacontane & 39.026 & 2.43 & - \\
\hline 3-Methylheptadecane & 40.266 & 1.53 & - \\
\hline n-Hexatriacontane & 42.212 & 1.91 & - \\
\hline n-Tetracosane & 43.068 & - & 0.69 \\
\hline Auraptene & 44.453 & 20.77 & - \\
\hline 2,2-Dimethyl-3-(3-methyl-5-phenylsulfanyl-pent-3-enyl)-oxirane & 45.903 & 3.98 & - \\
\hline Lycopersen & 46.323 & 1.97 & 0.18 \\
\hline trans-Caryophyllene & 48.047 & 0.22 & - \\
\hline 3-Adamantan-1-yl-2-amino-propionic acid & 49.247 & - & 0.23 \\
\hline$\alpha$-tocopheryl- $\beta$-d-mannoside & 49.721 & 0.84 & - \\
\hline Vitamin E & 49.755 & - & 0.21 \\
\hline $4^{\prime}, 5,6,7,8$-Pentamethoxyflavone & 50.677 & 1.29 & - \\
\hline$\delta$-5-Ergosterol & 51.344 & 3.51 & 2.14 \\
\hline Stigmasterol & 51.768 & 1.80 & 0.67 \\
\hline Obtusifoliol & 52.290 & 0.43 & 0.3 \\
\hline $24-\beta$-Ethyl-5- $\delta$-cholesten-3- $\beta$-ol & 52.678 & - & 3.51 \\
\hline Clionasterol & 52.714 & 6.34 & - \\
\hline Fucosterol & 52.910 & - & 0.24 \\
\hline $3,3^{\prime}, 4^{\prime}, 5,5^{\prime}, 7,8$-Heptamethoxyflavone & 53.036 & 2.33 & - \\
\hline 9,19-Cyclolanost-24-en-3-ol, acetate & 55.050 & - & 0.13 \\
\hline Friedelan-3-one & 57.061 & 0.31 & - \\
\hline
\end{tabular}

${ }^{a}$ Supercritical $\mathrm{CO}_{2}$ extract of fruit compounds tentatively identified based on retention index and elution order as well as the fragmentation pattern described in the literature.

${ }^{\mathrm{b}}$ Retention time.

${ }^{\mathrm{c}}$ Relative peak area percentage (peak area relative to the total peak area \%).

chromatin are associated with apoptotic cell death. To evaluate the effect of auraptene on proliferation and to characterize auraptene-induced apoptosis, SNU-1 cells were treated with or without various concentrations of auraptene and stained with Hoechst 33342 and then observed under fluorescence microscopy. As shown in Figure 3(a), after treatment with 25, 50 , and $100 \mu \mathrm{M}$ auraptene, SNU-1 cells showed morphological changes, including condensed and fragmented chromatin with dose-dependently increased apoptotic bodies (arrows). Cell cycle regulation is the major regulatory mechanism of cell growth. Many cytotoxic agents arrest the cell cycle at the G1, S, or G2/M phases, cause cells to accumulate in the subG1 phase, and then induce apoptotic cell death. In this study, signs of apoptosis were indicated by the increased sub-G1 SNU-1 cells after auraptene treatment in a concentration dependent manner. The sub-G1 population was increased from $4.80 \%(0 \mu \mathrm{M})$ to $23.45 \%(100 \mu \mathrm{M})$. In addition, low concentration of auraptene ( 25 and $50 \mu \mathrm{M})$ caused a significant increase in the G1 population (from $55.75 \%$ to 61.34 and $75.40 \%$, resp.) (Table 2). These data suggest that auraptene inhibits SNU-1 cell proliferation by inducing G1 cell cycle arrest at relatively lower concentrations and causing the accumulation of sub-G1 cells at higher concentrations. As depicted in Figure 3(b) auraptene caused a decrease in the mitochondrial membrane potential $(\Delta \Psi \mathrm{m})$ in a concentration dependent manner, from $85.66 \%$ at control to $12.13 \%$ at $100 \mu \mathrm{M}$. From these results it is clear that auraptene caused apoptotic cell death in SNU-1.

\subsection{Effects of Auraptene on the Regulation of Apoptosis Related} Proteins and PI3K/Akt/mTOR Signaling Pathway. Apoptosis is regulated by various types of modulators, such as caspases [14]. To determine the mechanism of auraptene-induced apoptosis, the regulation of apoptotic proteins was examined 


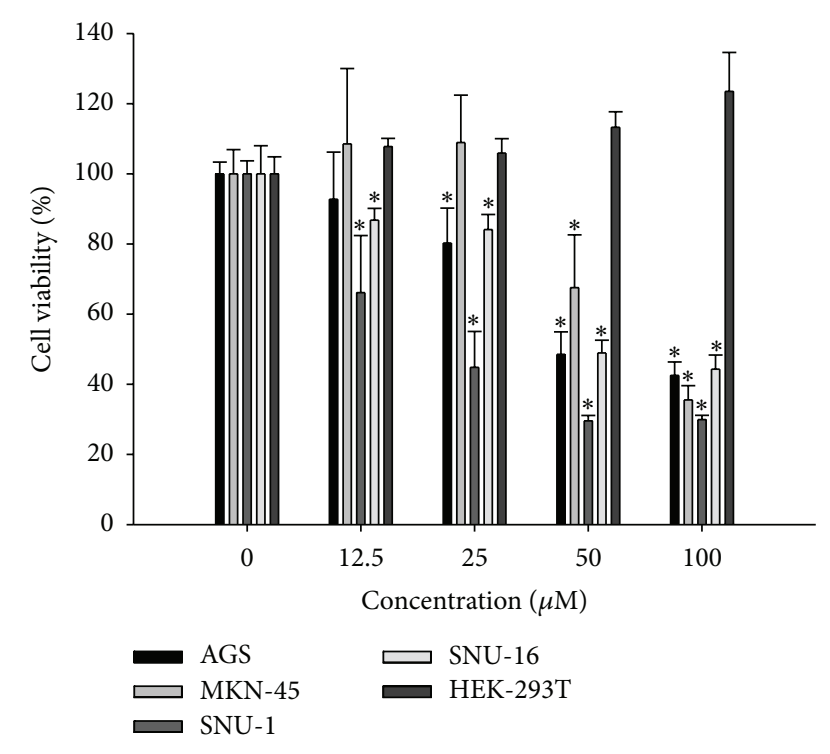

FIGURE 2: Cell growth inhibition by auraptene. Viability was determined on the basis of MTT reduction assay against various cancer cell lines and a noncancer cell line after treating with shown concentration of auraptene for $48 \mathrm{~h}$. (Data represent the means SD of at least four independent experiments. ${ }^{*} P<0.01$ indicate statistically significant differences versus control group.)

TABLE 2: The percentage of SNU-1 in each phase after treatment with auraptene for $24 \mathrm{~h}$.

\begin{tabular}{lcccc}
\hline & \multicolumn{4}{c}{ Auraptene $(\mu \mathrm{M})$} \\
& 0 & 25 & 50 & 100 \\
\hline Sub-G1 & $4.80 \pm 1.36$ & $7.34 \pm 3.17$ & $8.77 \pm 4.45$ & $23.45 \pm 7.34$ \\
G1 & $55.75 \pm 0.91$ & $61.34 \pm 2.19$ & $75.40 \pm 6.40$ & $51.36 \pm 4.77$ \\
S & $14.37 \pm 0.67$ & $12.08 \pm 1.35$ & $6.54 \pm 1.49$ & $10.36 \pm 0.13$ \\
G2/M & $25.59 \pm 0.54$ & $19.72 \pm 3.41$ & $9.65 \pm 2.10$ & $15.38 \pm 3.28$ \\
\hline
\end{tabular}

by western blotting. The protein level of effector caspase- 3 was decreased, whereas the level of cleaved form of caspase-3 was increased dose-dependently. Further, the level of proteolytically cleaved PARP was increased in a dose-dependent manner (Figure 4(a)). Cellular stress can activate p53, which induces cell cycle arrest or apoptosis. When DNA damage occurs, activated p53 halts the progression of cell cycle in the G1 phase to provide time for DNA repair. As illustrated in Figure 4(a), auraptene dose-dependently induced the phosphorylation of p53 and caused dose-dependent downregulation of cyclin D1, indicating that auraptene could induce cell cycle arrest in SNU-1 (Table 2). The PI3K/Akt/mTOR pathway is an intracellular signalling pathway important in cell growth and apoptosis. Therefore, we examined whether auraptene can regulate the PI3K/Akt/mTOR signaling pathway. As shown in Figure 4(b), the level of phospho-mTOR was decreased accompanied by downregulation of p-p70S6K and downstream of mTOR proteins. However, the level of phospho-Akt was increased, which is reminiscent of the effect of rapamycin, the mTOR inhibitor. Therefore, we tested whether auraptene can induce negative feedback loop on Akt/ mTOR signaling, the same as rapamycin (mTOR inhibitor) does in SNU-1 cells. As shown in Figure 4(c), both auraptene and rapamycin downregulate phosphorylation of mTOR and its downstream p70S6K but feedback activation of Akt in a similar pattern (Figure 4(c)). Altogether, these results suggest that auraptene could induce p53 dependent cell cycle arrest and apoptosis and furthermore, it could suppress the proliferation of SNU-1 cells by downregulation of mTOR downstream signalling.

\section{Discussion}

The use of carbon dioxide in the supercritical state has been shown to be an effective method for obtaining bioactive molecules from plants. Recent studies reported that supercritical fluid extraction (SFE) is the process of separating one component from another using supercritical fluids as the extracting solvent. In this study, we determined the cytotoxic effect of SFE from peel and flesh of phalsak (Citrus hassaku Hort ex Tanaka) on human gastric cancer SNU-1 cells and demonstrated that phalsak peel SFE significantly inhibits the cell viability. In most of the studies on the volatile composition of Citrus fruits obtained by conventional methods of extractions, limonene was found in a proportion of $>94.8 \%[15,16]$. However, in the present study limonene was found to be extremely low levels in phalsak. The discrepancy can be attributed to the supercritical extracts as well as the geographical origin of the samples.

Apoptosis is a compactly regulated process controlled by several signaling pathways, such as the death receptors and mitochondrial pathways [17]. Mitochondria are known to play a central role in mediating "intrinsic death signals" and could therefore serve as a novel target for chemotherapy. Cell cycle regulation is the major regulatory mechanism of cell growth. Many cytotoxic agents arrest the cell cycle at the G1, S, or G2/M phases, cause cells to accumulate in the sub-G1 phase, and induce apoptotic cell death. Our results indicated that auraptene induces cell cycle arrest at low concentration and increases the population in sub-G1 phase in a dose-dependent manner (Table 2). In addition, cells were undergoing apoptosis by disturbed mitochondria membrane potential and activation of apoptosis related proteins. It has been suggested that chemically induced apoptosis is often associated with the loss of $\Delta \Psi \mathrm{m}$ as a consequence of the leakiness of the inner mitochondrial membrane [18]. As depicted in Figure 3(b) auraptene caused a dramatic decrease in the mitochondrial membrane potential $(\Delta \Psi \mathrm{m})$ in a concentration dependent manner. The prevention of cancer is largely dependent on tumor suppressor protein p53. Cellular stress can activate p53 which induces cell cycle arrest or apoptosis. The choice between apoptosis or cell cycle arrest is influenced by many factors such as type of cell, stress, and action of p53 coactivators [19]. As illustrated in Figure 4(a) and Table 2, auraptene dose-dependently induced the phosphorylation of p53 and reduced the level of cyclin D1, indicating that activated p53 could halt the progression of cell cycle in G1 phase as well as induction of apoptosis. 


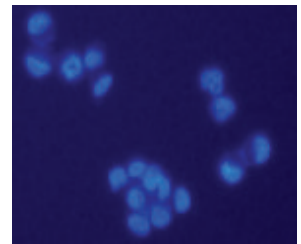

Control

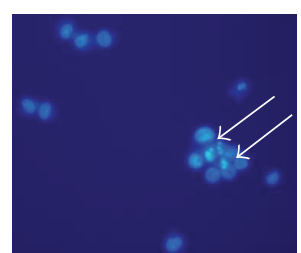

$50 \mu \mathrm{M}$

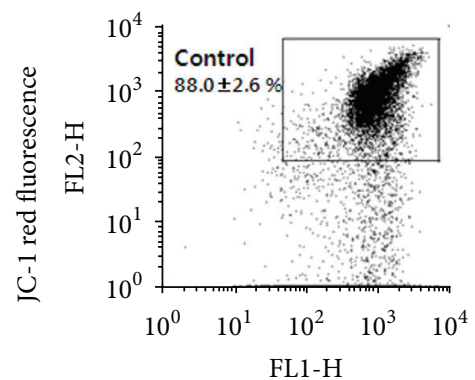

JC-1 green fluorescence

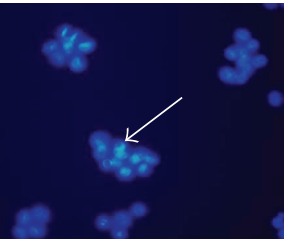

$25 \mu \mathrm{M}$

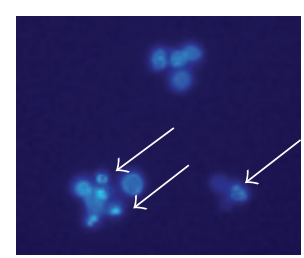

$100 \mu \mathrm{M}$

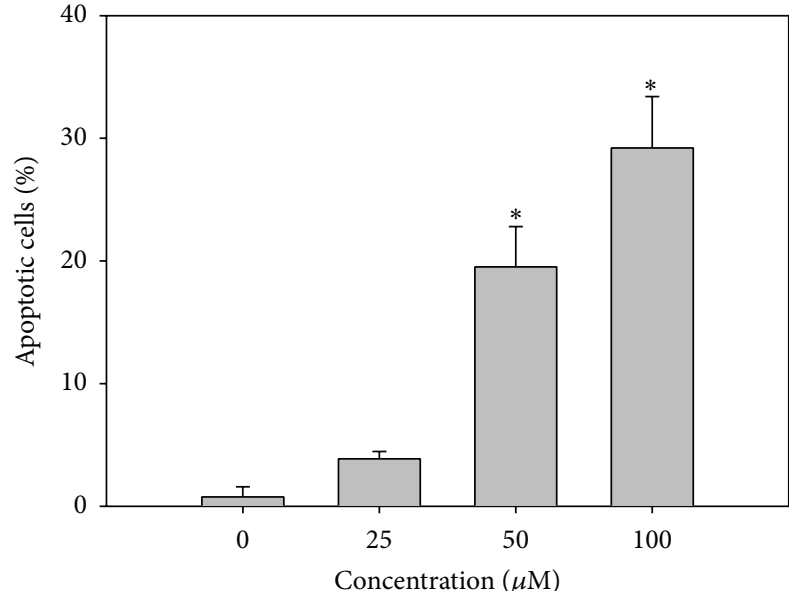

(a)

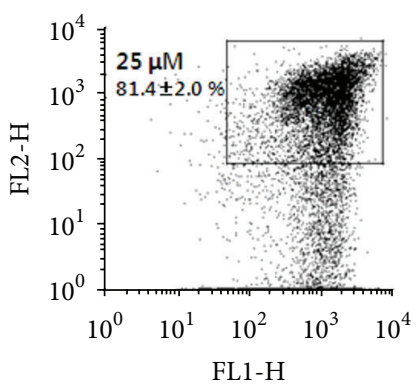

JC-1 green fluorescence

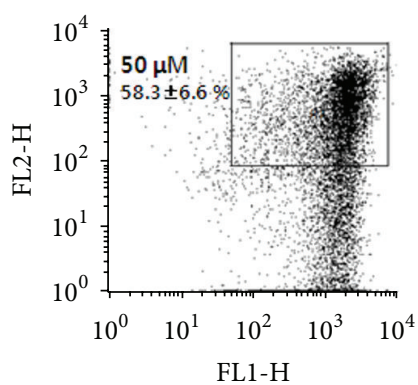

JC-1 green fluorescence

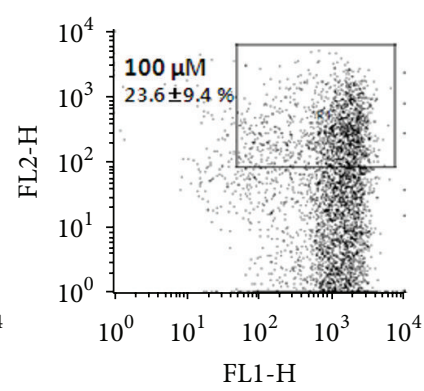

JC-1 green fluorescence

(b)

Figure 3: Nuclear Hoechst 33342 staining, cell cycle analysis, and determination of mitochondrial membrane potential. (a) Cells were treated with the indicated concentration of auraptene $(25-100 \mu \mathrm{M})$ for $24 \mathrm{~h}$ and then stained with Hoechst 33342 . Stained cells were visualized under a fluorescence microscope. (b) Mitochondrial membrane potential was determined by FACS caliber after being treated with given doses of auraptene. (Data represent the means SD of at least four independent experiments. ${ }^{*} P<0.01$ indicate statistically significant differences versus control group.)

The PI3K/Akt/mTOR pathway is involved in the regulation of cell growth and survival. Mammalian target of rapamycin (mTOR) is an essential component of intracellular signalling for cellular growth, mRNA translation, and metabolism. mTOR has been demonstrated to be involved in gene regulation and translation of specific transcripts when cells respond to environmental stimuli [20]. mTOR is regulated by mitogen-responsive pathways and it could be activated by PI3K/Akt pathways $[21,22]$. However, previous studies suggest that inhibition of p70S6K by the mTOR inhibitor rapamycin results in an increase of the IGF-1R/IRS1/PI3K (insulin-like growth factor receptor/insulin receptor substrate-1/phosphoinositide 3-kinase) signaling and activation of Akt. It has been reported that p70S6K mediates phosphorylation of IRS-1 inhibitory serine sites (S312 and/or S636/639) which lead to IRS-1 degradation [23, 24]. Thus, suppression of p70S6K activity by rapamycin may prevent inhibitory IRS-1 phosphorylation, thereby stabilizing IRS1. An increase in IRS-1 adapter protein levels may induce Akt activity by augmenting IGF-1R signaling to PI3K/Akt. These data indicate that mTOR inhibition by rapamycin induces negative feedback activation of Akt that is IGF-1R/ $\mathrm{PI} 3 \mathrm{~K}$ dependent. Interestingly, we noticed auraptene-induced phosphorylation of Akt but downregulation of mTOR and its downstream p70S6K (Figure 4(b)), indicating auraptene has effect of mTOR inhibition the same as rapamycin does in SNU-1 cells. Using human non-small cell lung cancer (NSCLC) cells, Sun et al. reported that mTOR inhibition by rapamycin induces activation of survival pathways involving increase of Akt and eIF4E phosphorylation. They showed that prevention or disruption of the activation of Akt and eIF4E enhanced rapamycin-mediated growth inhibition, indicating that the induced activation of Akt and eIF4E survival pathways counteracts the mTOR inhibitor's effect on the growth of human cancer cells [25]. It remains possible that mTOR inhibition induces Akt activation by other unknown mechanisms, such as indirect activation of mTOR-rictor by auraptene, which require further elucidation. Currently, the possibility that PI3K inhibitor and/or IGF-1R antibody in combination with auraptene can exhibit enhanced (synergistic) effects on the growth of human gastric cancer cells is under investigation in our laboratory. 

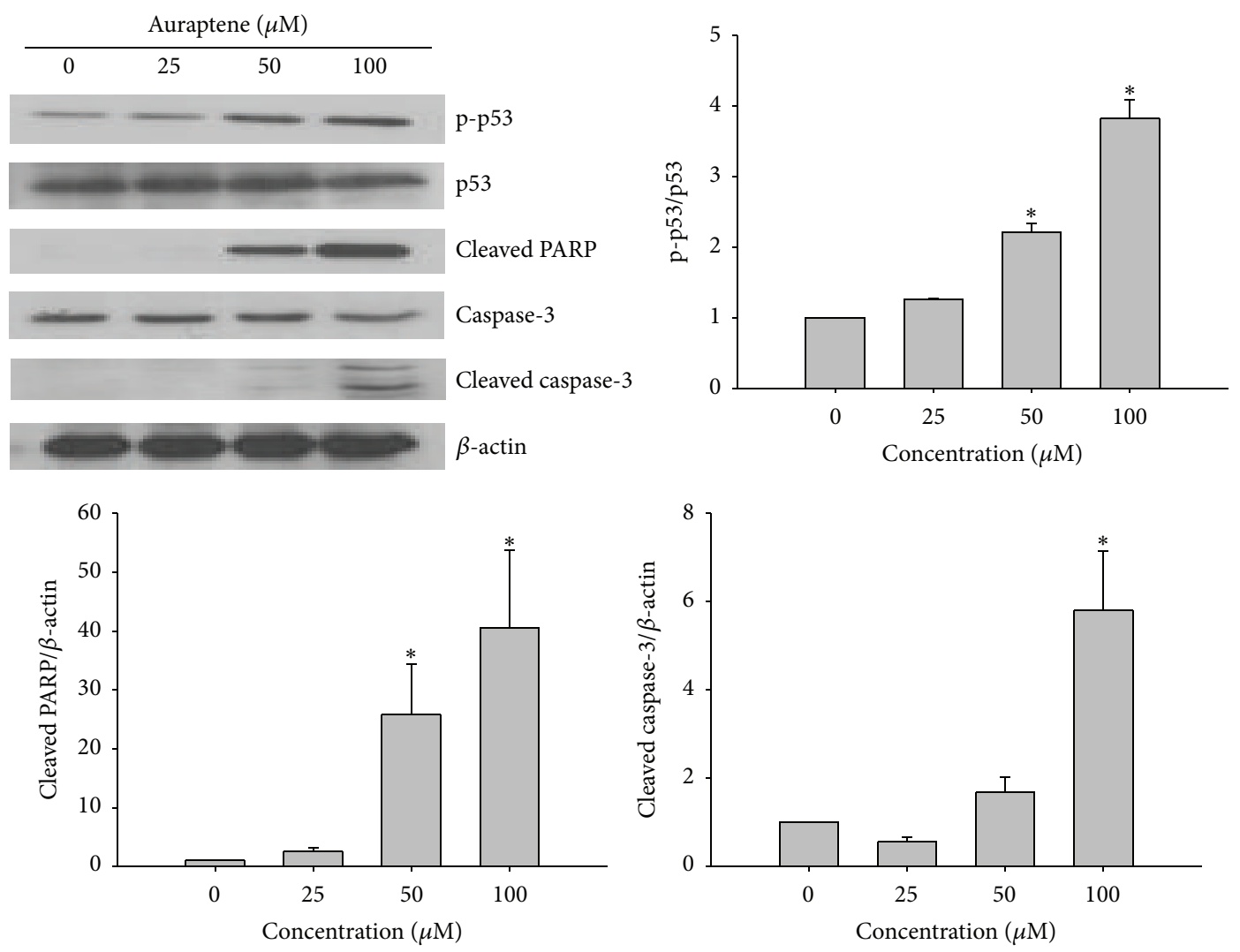

(a)
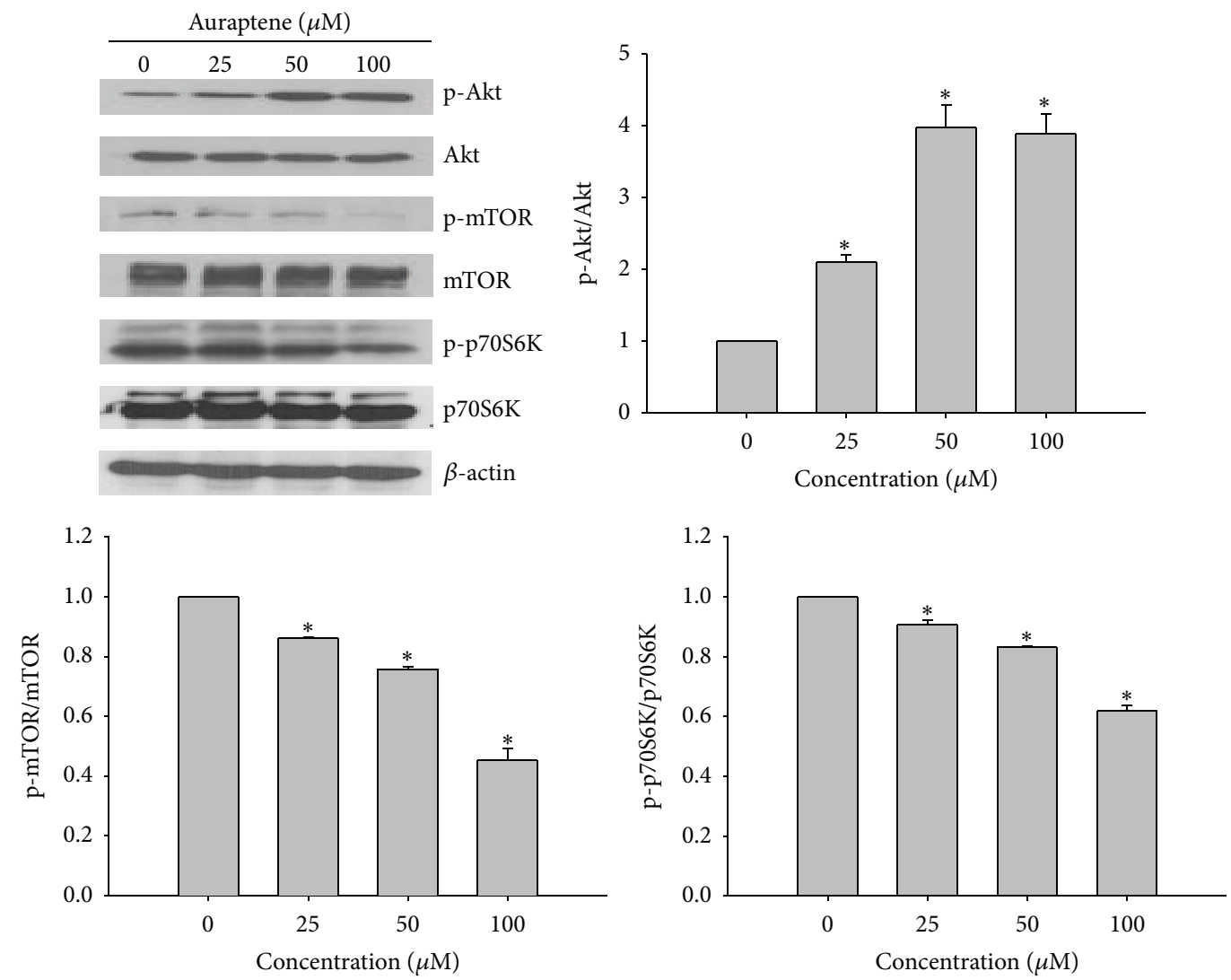

(b)

Figure 4: Continued. 

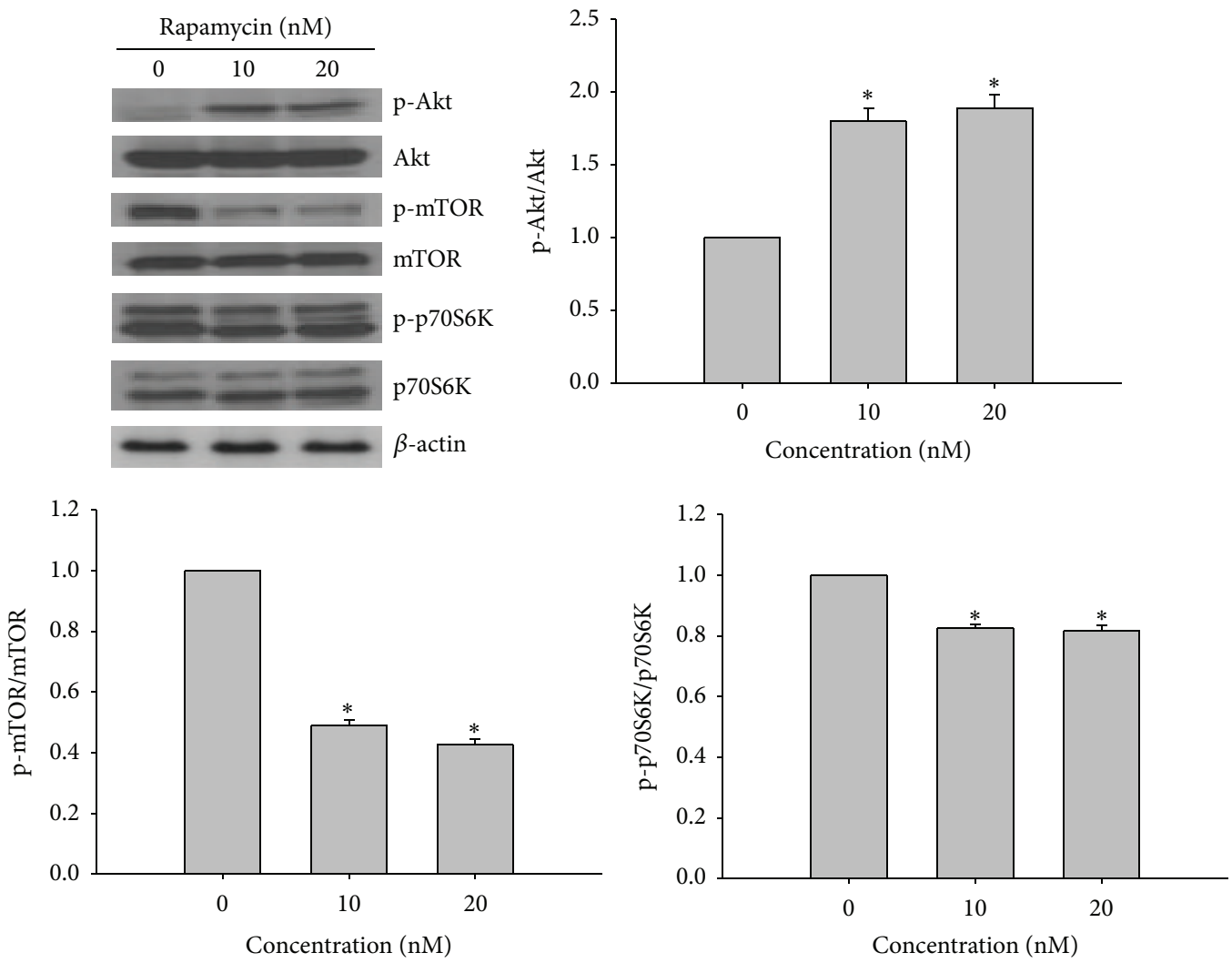

(c)

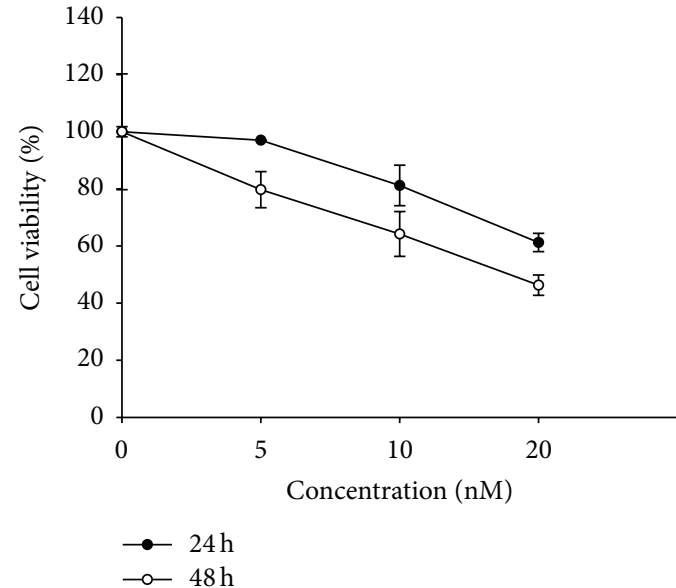

(d)

FIGURE 4: Western blot analysis of apoptosis and PI3K/Akt/mTOR related protein expression. (a) Cells were lysed after incubation with different concentrations of auraptene $(25-100 \mu \mathrm{M})$. After $24 \mathrm{~h}$, cell lysates were subjected to western blotting as mentioned in the method. (b) Western blotting for the effect of auraptene on Akt/mTOR related proteins in SNU-1 cells. (c) Cells were treated with rapamycin for $24 \mathrm{~h}$ in SNU-1 cells. $\beta$-actin was used as an internal control. (d) Cell growth inhibition by rapamycin. Viability was determined on the basis of MTT reduction assay against SNU-1 cells for 24 and $48 \mathrm{~h}$. (Data represent the means SD of at least four independent experiments. ${ }^{*} P<0.01$ indicate statistically significant differences versus control group.) 
Taken together, we found that auraptene, a major component in phalsak peel SFE, induces cell cycle arrest and apoptosis in SNU-1 cells via activation of p53 and inhibition of mTOR signaling pathway accompanied by negative feedback activation of Akt.

\section{Conflict of Interests}

The authors declare that they have no conflict of interests.

\section{Acknowledgment}

This research was supported by the Basic Science Research Program through the National Research Foundation of Korea (NRF) funded by the Ministry of Education (2014047495) and by the Ministry of Education (2013R1A1A2064103).

\section{References}

[1] R. Liu, Z. Li, S. Bai et al., "Mechanism of cancer cell adaptation to metabolic stress: proteomics identification of a novel thyroid hormone-mediated gastric carcinogenenic signaling pathway," Molecular and Cellular Proteomics, vol. 8, no. 1, pp. 70-85, 2009.

[2] M. Plummer, S. Franceschi, and N. Muñoz, "Epidemiology of gastric cancer," IARC Scientific Publications, vol. 157, pp. 311-326, 2004.

[3] P. Yang, Y. Zhou, B. Chen et al., "Overweight, obesity and gastric cancer risk: results from a meta-analysis of cohort studies," European Journal of Cancer, vol. 45, no. 16, pp. 2867-2873, 2009.

[4] N. Lunet, C. Valbuena, A. L. Vieira et al., "Fruit and vegetable consumption and gastric cancer by location and histological type: case-control and meta-analysis," European Journal of Cancer Prevention, vol. 16, no. 4, pp. 312-327, 2007.

[5] M.-C. Lin, M.-J. Tsai, and K.-C. Wen, "Supercritical fluid extraction of flavonoids from Scutellariae Radix," Journal of Chromatography A, vol. 830, no. 2, pp. 387-395, 1999.

[6] S. Kawaii, Y. Tomono, E. Katase, K. Ogawa, and M. Yano, "Antiproliferative activity of flavonoids on several cancer cell lines," Bioscience, Biotechnology and Biochemistry, vol. 63, no. 5, pp. 896-899, 1999.

[7] A. Sahebkar, "Citrus auraptene: a potential multifunctional therapeutic agent for nonalcoholic fatty liver disease," Annals of Hepatology, vol. 10, no. 4, pp. 575-577, 2011.

[8] H. Kohno, R. Suzuki, M. Curini et al., "Dietary administration with prenyloxycoumarins, auraptene and collinin, inhibits colitis-related colon carcinogenesis in mice," International Journal of Cancer, vol. 118, no. 12, pp. 2936-2942, 2006.

[9] A. Hara, K. Sakata, Y. Yamada et al., "Suppression of betacatenin mutation by dietary exposure of auraptene, a citrus antioxidant, in N,N-diethylnitrosamineinduced hepatocellular carcinomas in rats," Oncology Reports, vol. 14, no. 2, pp. 345-351, 2005.

[10] A. Murakami, W. Kuki, Y. Takahashi et al., "Auraptene, a Citrus coumarin, inhibits 12-O-tetradecanoylphorbol-13-acetateinduced tumor promotion in ICR mouse skin, possibly through suppression of superoxide generation in leukocytes," Japanese Journal of Cancer Research, vol. 88, no. 5, pp. 443-452, 1997.

[11] A. Murakami, Y. Nakamura, T. Tanaka et al., "Suppression by citrus auraptene of phorbol ester-and endotoxin-induced inflammatory responses: role of attenuation of leukocyte activation," Carcinogenesis, vol. 21, no. 10, pp. 1843-1850, 2000.
[12] D. Y. Jun, J. S. Kim, H. S. Park et al., "Apoptogenic activity of auraptene of Zanthoxylum schinifolium toward human acute leukemia Jurkat $\mathrm{T}$ cells is associated with ER stress-mediated caspase- 8 activation that stimulates mitochondria-dependent or -independent caspase cascade," Carcinogenesis, vol. 28, no. 6, pp. 1303-1313, 2007.

[13] M. Curini, G. Cravotto, F. Epifano, and G. Giannone, "Chemistry and biological activity of natural and synthetic prenyloxycoumarins," Current Medicinal Chemistry, vol. 13, no. 2, pp. 199222, 2006.

[14] E. Ulukaya, C. Acilan, and Y. Yilmaz, "Apoptosis: why and how does it occur in biology?" Cell Biochemistry and Function, vol. 29, no. 6, pp. 468-480, 2011.

[15] G. M. Kamal, F. Anwar, A. I. Hussain, N. Sarri, and M. Y. Ashraf, "Yield and chemical composition of Citrus essential oils as affected by drying pretreatment of peels," International Food Research Journal, vol. 18, no. 4, pp. 1275-1282, 2011.

[16] J. R. Patil, G. K. Jayaprakasha, K. N. Chidambara Murthy, S. E. Tichy, M. B. Chetti, and B. S. Patil, "Apoptosis-mediated proliferation inhibition of human colon cancer cells by volatile principles of Citrus aurantifolia," Food Chemistry, vol. 114, no. 4, pp. 1351-1358, 2009.

[17] S. Elmore, "Apoptosis: a review of programmed cell death," Toxicologic Pathology, vol. 35, no. 4, pp. 495-516, 2007.

[18] X.-M. Sun, M. MacFarlane, J. Zhuang, B. B. Wolf, D. R. Green, and G. M. Cohen, "Distinct caspase cascades are initiated in receptor-mediated and chemical-induced apoptosis," The Journal of Biological Chemistry, vol. 274, no. 8, pp. 5053-5060, 1999.

[19] S. A. Amundson, T. G. Myers, and A. J. Fornace Jr., "Roles for p53 in growth arrest and apoptosis: Putting on the brakes after genotoxic stress," Oncogene, vol. 17, no. 25, pp. 3287-3299, 1998.

[20] A.-C. Gingras, B. Raught, and N. Sonenberg, "mTOR signaling to translation," Current Topics in Microbiology and Immunology, vol. 279, pp. 169-197, 2003.

[21] C. M. Maya-Monteiro and P. T. Bozza, "Leptin and mTOR: partners in metabolism and inflammation," Cell Cycle, vol. 7, no. 12, pp. 1713-1717, 2008.

[22] C. M. Maya-Monteiro, P. E. Almeida, H. D’Ávila et al., "Leptin induces macrophage lipid body formation by a phosphatidylinositol 3-kinase- and mammalian target of rapamycindependent mechanism," The Journal of Biological Chemistry, vol. 283, no. 4, pp. 2203-2210, 2008.

[23] S. H. Um, F. Frigerio, M. Watanabe et al., "Absence of S6K1 protects against age- and diet-induced obesity while enhancing insulin sensitivity," Nature, vol. 431, no. 7005, pp. 200-205, 2004.

[24] B. D. Manning, "Balancing Akt with S6K: implications for both metabolic diseases and tumorigenesis," Journal of Cell Biology, vol. 167, no. 3, pp. 399-403, 2004.

[25] S.-Y. Sun, L. M. Rosenberg, X. Wang et al., "Activation of Akt and eIF4E survival pathways by rapamycin-mediated mammalian target of rapamycin inhibition," Cancer Research, vol. 65, no. 16, pp. 7052-7058, 2005. 


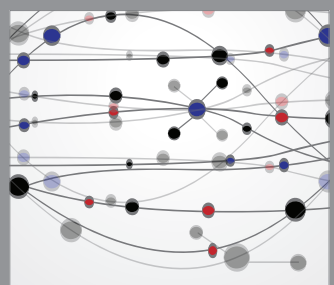

The Scientific World Journal
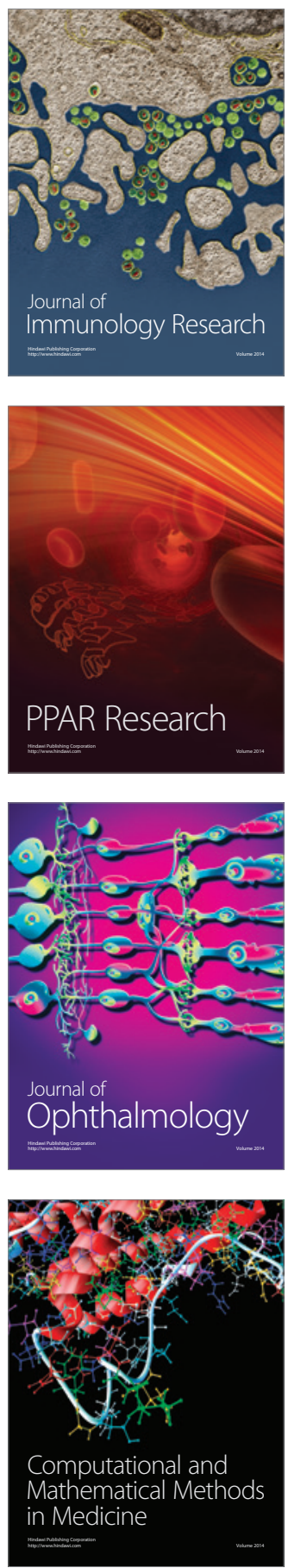

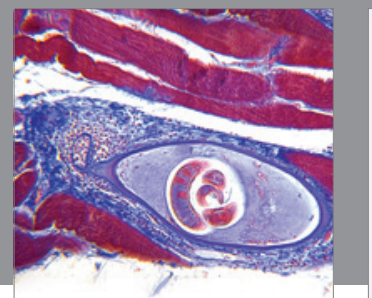

Gastroenterology

Research and Practice
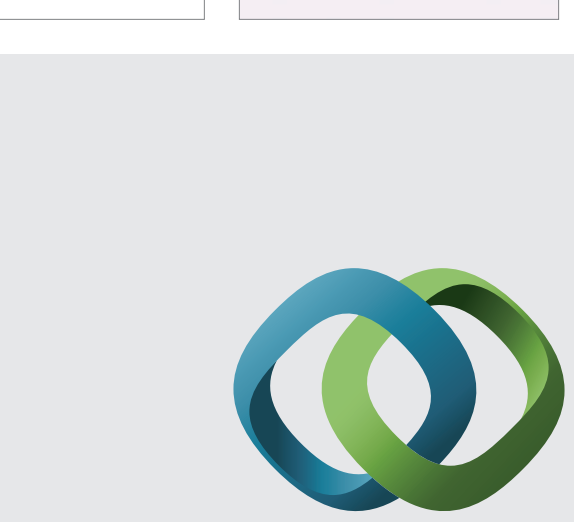

\section{Hindawi}

Submit your manuscripts at

http://www.hindawi.com
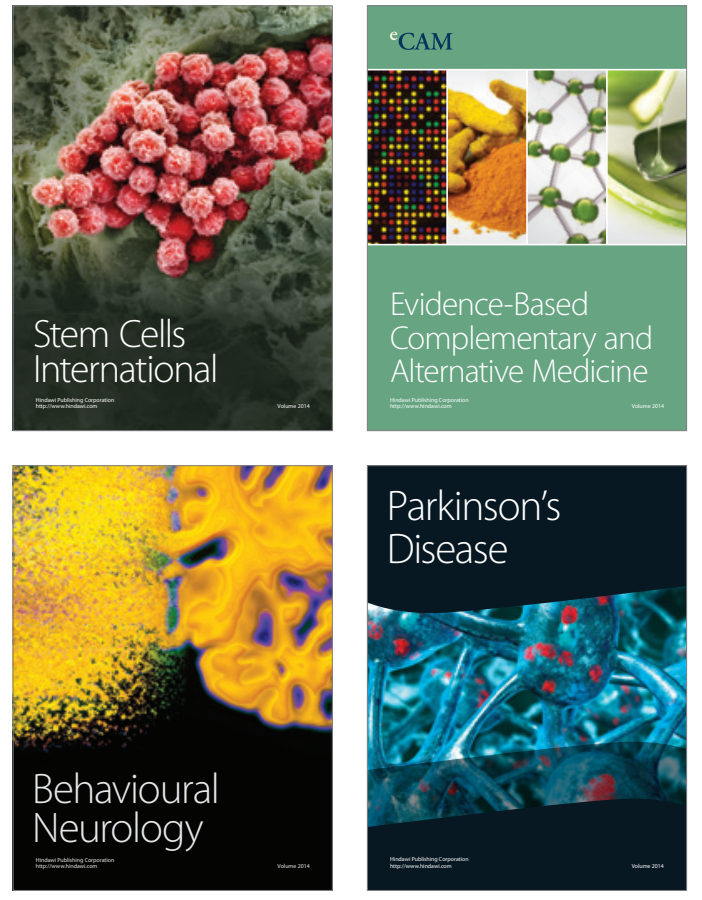
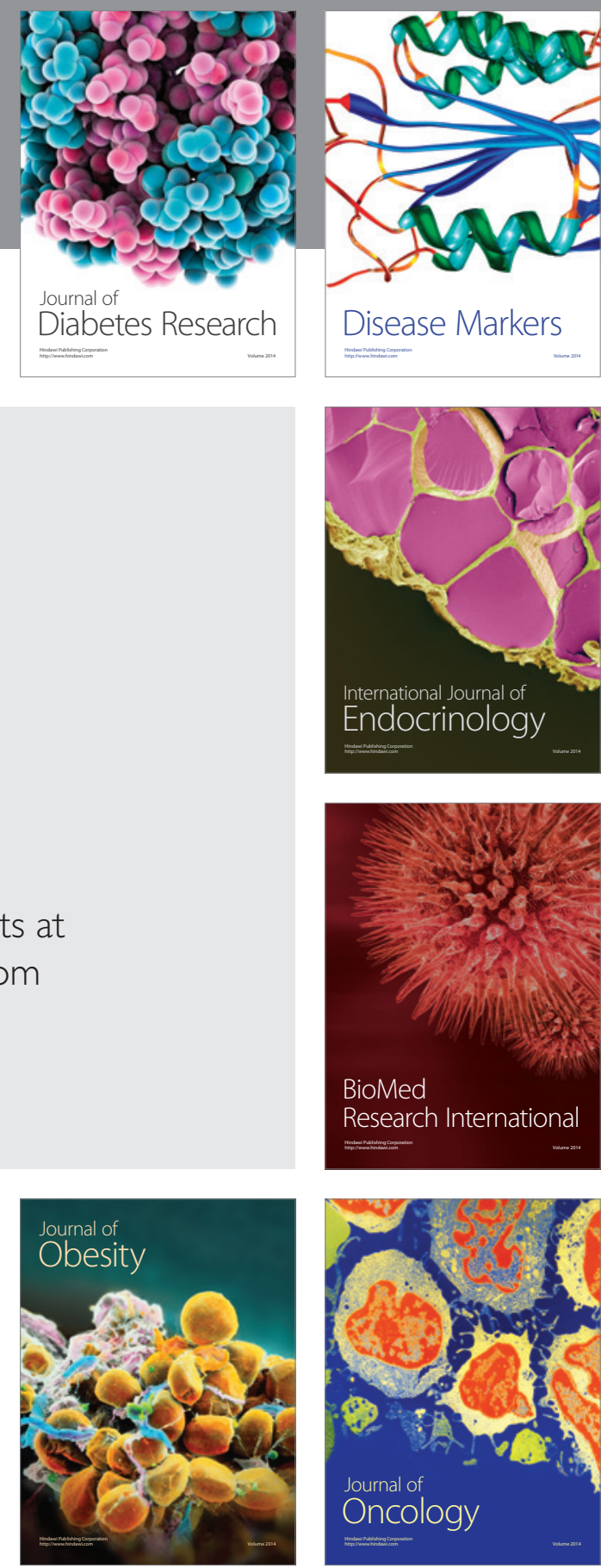

Disease Markers
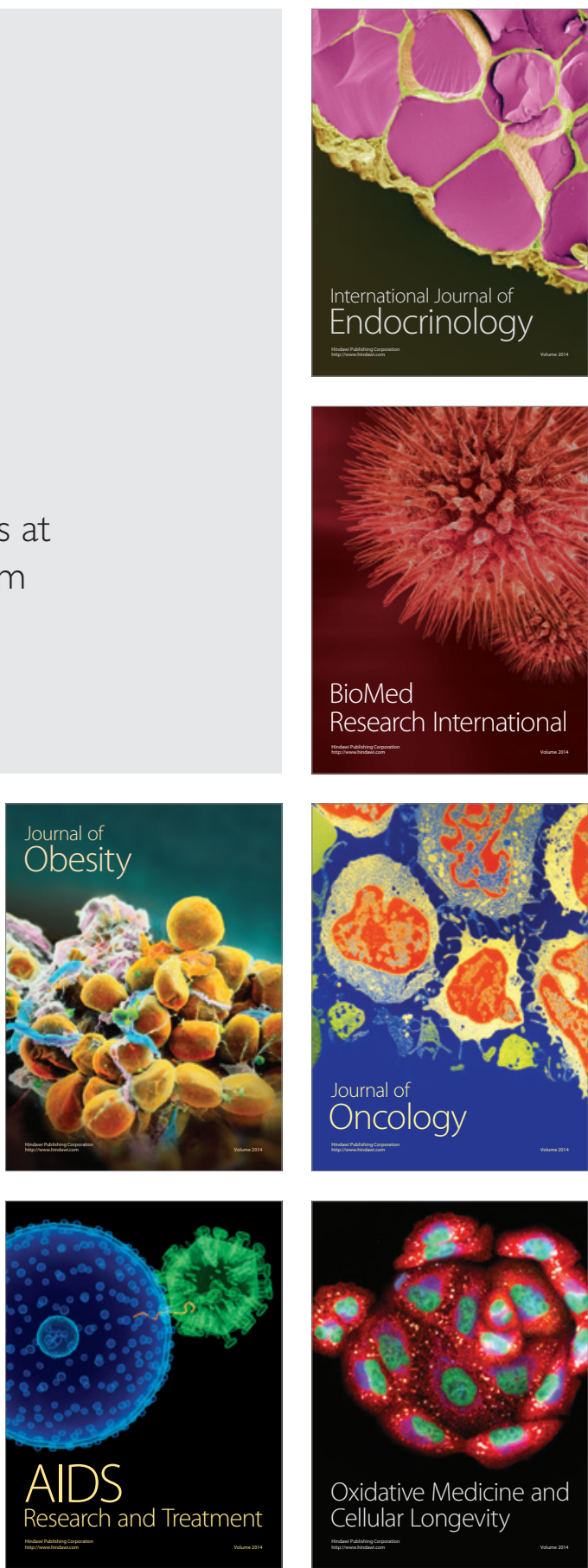